\title{
CORRELATION OF DENTAL AND CHRONOLOGICAL AGE AMONG A GROUP OF 130 CHILDREN FROM THE LOWER SILESIAN POPULATION
}

\author{
Izabela Wujec-Lizis, Aleksa Mucha, Sylwia Zabłocka-Oczoś \\ Department of Maxillofacial Orthopaedics and Orthodontics, Medical University of Wroclaw, Poland
}

\begin{abstract}
INTRODUCTION: Dental age is one of the methods used to determine the physiological age, and the assessment thereof is essential for many branches of science. The standard of general dental and orthodontic diagnostics is a pantomographic image, which can be applied to assess the dental age using the Demirjian method.

Овјестіves: Determination of the current dental age in the group of children of the lower Silesian population, comparison of the results with data determined using the Demirjian method, and calculation of possible deviations.

MATERIAL AND METHODs: The research group consisted of 130 Caucasian children (64 girls and 66 boys) aged between 7 and 13 years. The Demirjian method was used to assess the dental age. The following tests were applied: Shapiro-Wilk test, Levene's test, Wilcoxon rank-sum test, Welch's test, Tukey's honest significant difference (HSD) test, $\chi^{2}$ test, and Spearman's rank correlation coefficient. For the purposes of the study, the significance level was established as $p<0.05$.

RESUlTs: Without division into age groups, the chronological age was ahead of dental maturation, both for girls and boys. It was shown that the difference between the chronological and dental age increases with the rise in chronological maturation, in favour of the chronological age. Based on tests determining whether gender constitutes a factor influencing the calculated value of age differences, the obtained results were statistically insignificant.

ConcLusions: The research conducted by the authors shows that in the analysed group the dental age was accelerated in the period of early mixed dentition and delayed in the late mixed or early permanent dentition stage, in relation to the chronological age. Therapeutic decisions made by the orthodontist should be based on the analysis of the child's actual dental age and should not take into account the chronological age.
\end{abstract}

KEY WORDS: dental age, chronological age, Demirjian.

J Stoma 2020; 73, 4: 176-182

DOI: https://doi.org/10.5114/jos.2020.98313

\section{INTRODUCTION}

Dental age is one of the parameters used to determine physiological age, and the assessment thereof is essential for many branches of science. It is helpful in criminology and forensic medicine for the identification of a corpse. It can also be applied to estimate the age of a living person who does not possess reliable documents proving his/her date of birth [1]. It also contributes to cognitive research, e.g. in archaeological
JOURNAL OF STOMATOLOGY CZASOPISMO STOMATOLOGICZNE
AdDRESS FOR CORRESPONDENCE: Izabela Wujec-Lizis, Department of Maxillofacial Orthopaedics and Orthodontics, Medical University of Wroclaw, 26 Krakowska St., 50-425 Wroclaw, Poland, e-mail: izka.wujec@gmail.com

ReCEIVED: 04.05.2020 • ACCEPTED: 19.07.2020 • PuBlished: 30.08.2020 
works. At the same time, it may be significant in dentistry for planning the commencement of orthodontic treatment.

The alterations that take place in the human body, related to the development of teeth buds, are schematic and structured, which makes them easy to determine. The methods used to assess the dental age can be based on the time of teeth eruption and/or the degree of mineralisation of teeth buds. One of the most popular and well-documented methods of determining dental age is the Demirjian method, which assesses the developmental stages of left mandibular teeth using a pantomographic image. Such an image is a standard element of orthodontic and general dental diagnostics, and therefore does not require exposure to additional radiation. Similarly to all other methods, the procedure consists of comparing the actual stage of tooth bud development with the corresponding chronological age, determined in population studies.

However, in order for these analyses to be as accurate as possible, it is essential that the population data available is up to date, so it requires periodic verification. Unfortunately, at present there are few studies on the contemporary population of Polish children. For this reason, the authors undertook a study to determine the current dental age in the group of chil-

TABLE 1. Division of the study group

\begin{tabular}{|l|c|}
\hline Group 7-13 years old & Girls, $\boldsymbol{n = 6 4}$ \\
\hline Subgroup 7-9 years old & 20 \\
\hline Subgroup $>$ 9-11 years old & 21 \\
\hline Subgroup $>11-13$ years old & 23 \\
\hline
\end{tabular}

dren of the lower Silesian population and to compare it with the data determined by Demirjian, as well as to calculate possible deviations.

\section{MATERIAL AND METHODS}

The research was a retrospective study.

Initial analysis of panoramic radiographs and diagnosis consisted of 286 patients. 142 panoramic radiographs were rejected due to clefts, syndromes, congenitally missed teeth, premature loss of primary teeth due to caries or trauma, impacted teeth, and ethnicity other than Caucasian. Fourteen panoramic radiographs were rejected due to poor quality of X-ray (Figure 1).

Finally, the study group consisted of documentation of 130 Caucasian children (64 girls and 66 boys) (Table 1), aged 7-13 years, in whom a panoramic image was ordered to be performed for various dental indications.

All digital X-rays were taken in the Academic Stomatology Polyclinic (X-ray Orthophos XG 3). All panoramic images were analysed on a 22 -inch medical screen (Barco Eonis), always in the same room, and with curtained windows.

The dental age assessment was always performed by one person (postgraduate student on the last year of orthodontic specialisation - qualified in that field - Artium Magister [A.M.]). The researchers did not know the chronological age of the examined patients.

For the purpose of verification, $10 \%$ of the measurements were re-evaluated by an experienced orthodontist. This second observer randomly opened 10\% of the X-rays gathered in the base (folder) by opening the subfolders tagged with numbers and evaluated the dental age. Then the diagnosis was compared with

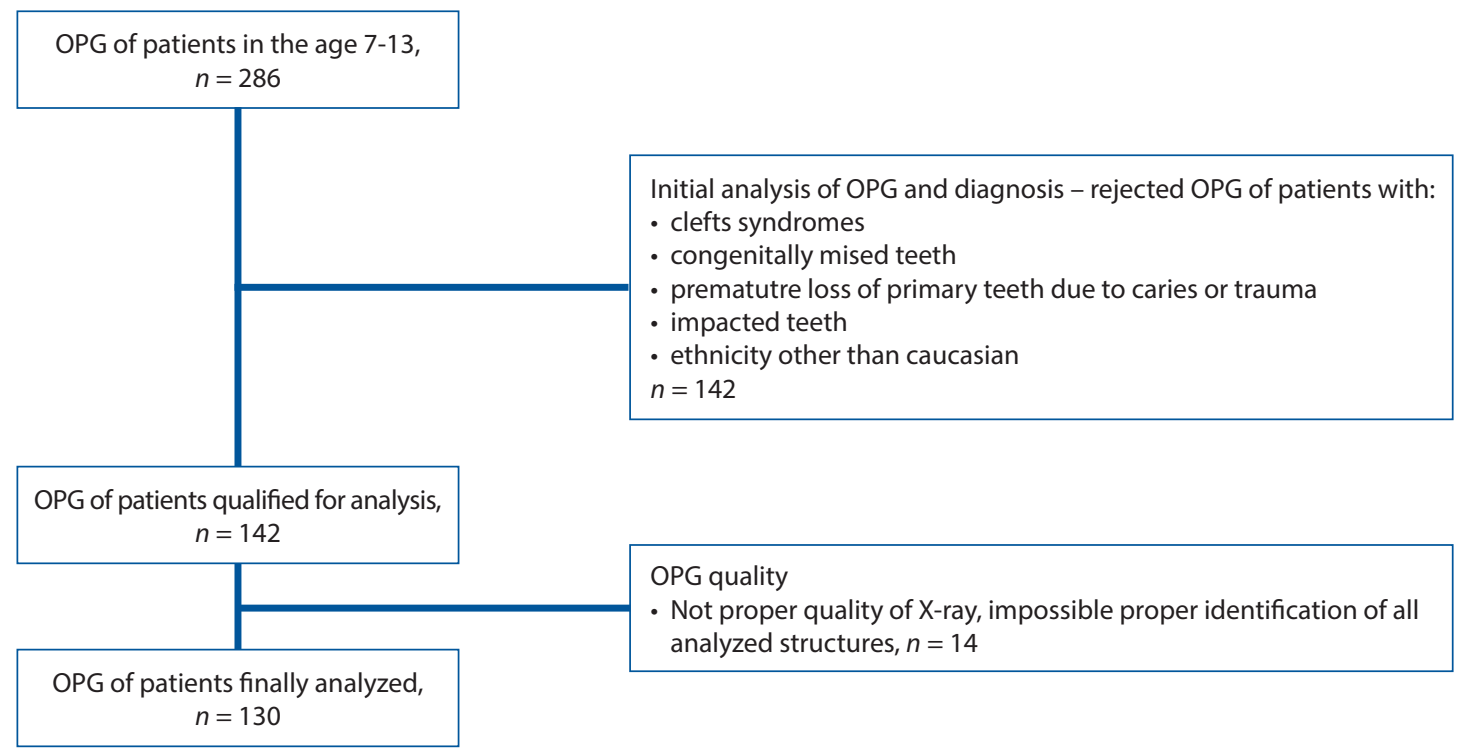

FIGURE 1. Flowchart of the study 

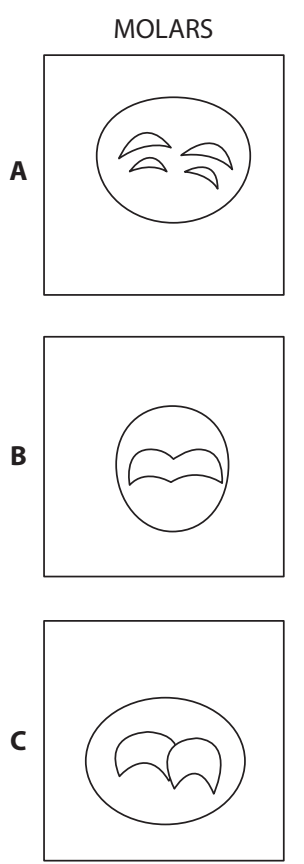

D

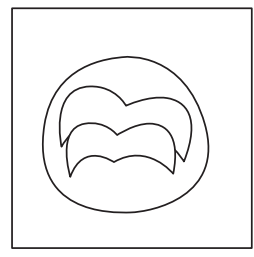

E

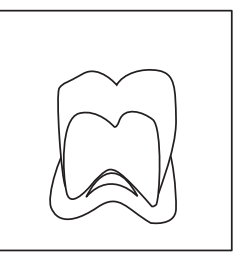

$\mathbf{F}$

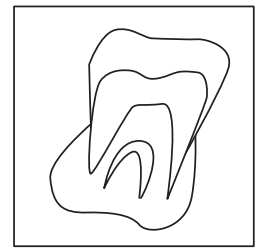

G

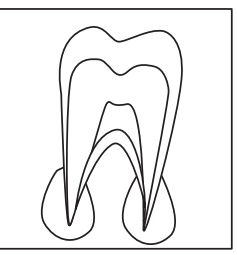

H

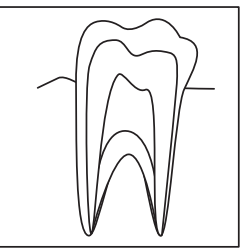

BICUSPIIDS
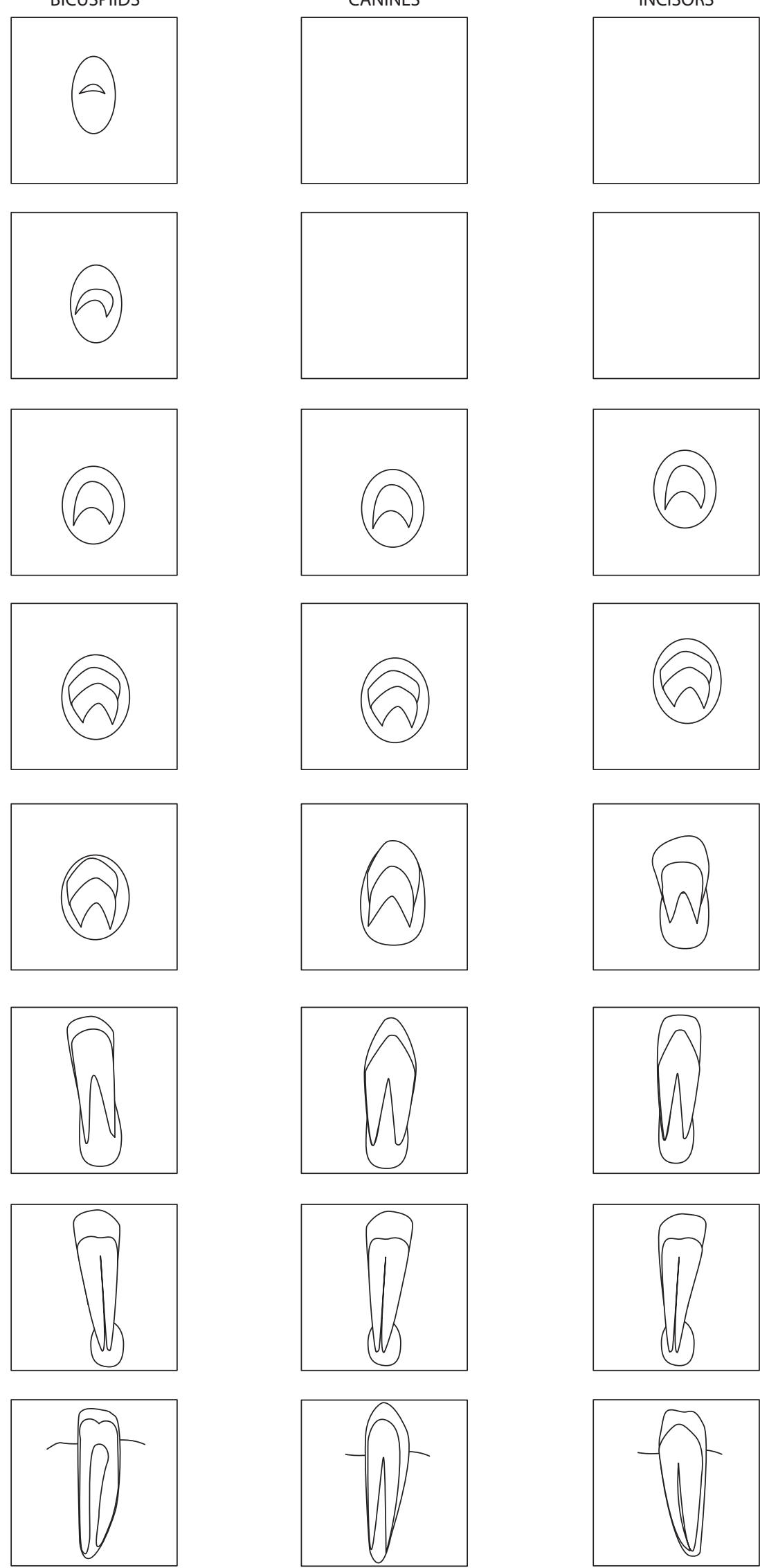

Schematic representation for eight stages of development

FIGURE 2. Graphical presentation of developmental stages according to the Demirjian method [3] 
the diagnosis of the first observer. Because full agreement was demonstrated in assessing the dental age between first and second observer, the selected correlation was not further studied statistically.

The Demirjian method was used in the study. It consists in assessing seven permanent teeth on the left side of the mandible and classifying them according to eight stages of their development. No evidence of mineralisation was determined as stage " 0 ", then its first symptoms were referred to as stage A, and sequentially until the moment when root apices are closed - i.e. stage $\mathrm{H}$ (Figure 2). All the teeth to be assessed were assigned a maturity point (0-8 points). By summing up each number, it is possible to obtain a result determining the dental age according to the table, which differs for women and men [2].

The obtained data were analysed statistically with the help of Statistica 10.0 (StatSoft Inc., USA). Calculations were made for both the whole group and after distinguishing three age subgroups, each broken down by gender (Tables 2-5). The following tests were applied: Shapiro-Wilk test, Levene's test, Wilcoxon rank-sum test, Welch's test, Tukey's honest significant difference (HSD) test, $\chi^{2}$ test, and Spearman's rank correlation coefficient. The significance level was established as $p<0.05$.

\section{RESULTS}

All results are presented in Tables 2-5.

With no division into age groups, it was determined that the chronological age was ahead of dental maturation by four months on average, both in the case of girls and boys (Table 2 ).

For the breakdown by gender and age group, see Table 3 .

Also, a correlation analysis was carried out to determine whether there is a regularity whereby the difference between the values rises as the chronological age increases. For both boys and girls, statistically significant average positive correlations were found (the difference between the chronological and dental age increases with the rise in the chronological age, in favour of the chronological age). The strength of the relationship is slightly stronger in the group of boys (Table 4).

It was analysed whether gender influences differences between chronological and dental age. The results presented in Table 5 are statistically insignificant. Therefore, there is no basis for assuming the hypothesis that gender constitutes a factor influencing the calculated value of these differences.

TABLE 2. Comparison of chronological and dental age without division into age group

\begin{tabular}{|c|c|c|c|c|c|c|c|c|}
\hline & Variable & $n$ & $\begin{array}{c}\text { Average } \\
\text { (months) }\end{array}$ & $\begin{array}{c}\text { Median } \\
\text { value }\end{array}$ & Minimum & Maximum & $\begin{array}{l}\text { Standard } \\
\text { deviation }\end{array}$ & $p$ \\
\hline \multirow{2}{*}{ Girls } & Chronological age & \multirow{2}{*}{64} & 120.86 & 121.5 & 85 & 153 & 20.30 & \multirow{2}{*}{0.049} \\
\hline & Dental age & & 116.20 & 112.5 & 85 & 175 & 20.40 & \\
\hline \multirow{2}{*}{ Boys } & Chronological age & \multirow{2}{*}{66} & 118.88 & 119 & 85 & 155 & 19.84 & \multirow{2}{*}{0.005} \\
\hline & Dental age & & 114.48 & 115 & 85 & 175 & 19.54 & \\
\hline
\end{tabular}

TABLE 3. Comparison of chronological and dental age with division into age group and gender

\begin{tabular}{|c|c|c|c|c|c|c|c|c|}
\hline Age & Sex & Variable & Average & Standard deviation & Difference & $p$ & Higher indicator & Type of test \\
\hline \multirow{4}{*}{$7-9$ years old } & \multirow{2}{*}{ Girls } & Chronological age & 96.85 & 5.949569 & \multirow{2}{*}{-4.1} & \multirow{2}{*}{0.042979} & \multirow{2}{*}{ * } & \multirow{8}{*}{$\begin{array}{l}t \text {-test for } \\
\text { dependent } \\
\text { tests }\end{array}$} \\
\hline & & Dental age & 100.95 & 9.433842 & & & & \\
\hline & \multirow{2}{*}{ Boys } & Chronological age & 95.72727 & 5.993503 & \multirow{2}{*}{-0.90909} & \multirow{2}{*}{0.603065} & \multirow{2}{*}{ n.s. } & \\
\hline & & Dental age & 96.63636 & 6.425733 & & & & \\
\hline \multirow{4}{*}{$>9-11$ years old } & \multirow{2}{*}{ Girls } & Chronological age & 119.2381 & 6.72982 & \multirow{2}{*}{5.47619} & \multirow{2}{*}{0.030431} & \multirow{2}{*}{ * } & \\
\hline & & Dental age & 113.7619 & 15.00968 & & & & \\
\hline & \multirow{2}{*}{ Boys } & Chronological age & 119.6957 & 6.86516 & \multirow{2}{*}{5.217391} & \multirow{2}{*}{0.064495} & \multirow{2}{*}{ n.s. } & \\
\hline & & Dental age & 114.4783 & 14.29199 & & & & \\
\hline \multirow{4}{*}{$>11-13$ years old } & \multirow{2}{*}{ Girls } & Chronological age & 143.2174 & 7.73397 & \multirow{2}{*}{11.5217} & \multirow{2}{*}{0.011097} & \multirow{2}{*}{ * } & \multirow{4}{*}{$\begin{array}{c}\text { Wilcoxon } \\
\text { [rank-sum] test }\end{array}$} \\
\hline & & Dental age & 131.6957 & 21.04202 & & & & \\
\hline & \multirow{2}{*}{ Boys } & Chronological age & 142.2381 & 5.13717 & \multirow{2}{*}{9.0476} & \multirow{2}{*}{0.00947} & \multirow{2}{*}{ * } & \\
\hline & & Dental age & 133.1905 & 15.96126 & & & & \\
\hline
\end{tabular}


TABLE 4. Differences between chronological and dental age depending on the gender

\begin{tabular}{|l|c|c|c|c|}
\hline \multicolumn{2}{|c|}{ Pair of variables } & Gender & $\boldsymbol{n}$ & $\boldsymbol{R}$ \\
\hline \multirow{2}{*}{ Chronological age \& dental age difference (months) } & Girls & 64 & 0.34 & 0.006109 \\
\cline { 2 - 5 } & Boys & 66 & 0.39 & 0.001194 \\
\hline
\end{tabular}

TABLE 5. Differences (in months) divided into age groups and gender

\begin{tabular}{|c|c|c|c|c|c|}
\hline \multirow{2}{*}{ Variable } & \multirow{2}{*}{ Group } & \multicolumn{2}{|c|}{ Average difference } & \multicolumn{2}{|c|}{ N significant } \\
\hline & & Boys & Girls & Boys & Girls \\
\hline \multirow{4}{*}{ Difference (months) } & 7-13 years old & 4.39 & 4.66 & 66 & 64 \\
\hline & 7-9 years old & -0.91 & -4.10 & 22 & 20 \\
\hline & 9-11 years old & 5.22 & 5.48 & 23 & 21 \\
\hline & $11-13$ years old & 9.05 & 11.52 & 21 & 23 \\
\hline
\end{tabular}

\section{DISCUSSION}

The methods used to assess dental age can be divided into techniques based on the time of eruption in different teeth groups and those taking into account the degree of mineralisation of permanent tooth buds.

The first group comprises the Schour and Massler method, in which the pantomographic image is compared to tables that present the time of eruption of whole dentition groups. Methods developed by Matiegka and Lukasova, Masztalerz and Bujwidowa, as well as Charzewski and Panek, constitute more precise clinical techniques. The aforementioned procedures determine the dental age based on tables or growth charts that specify the order, number, and type of the erupted permanent teeth.

The second group includes methods that take into account the degree of mineralisation of permanent tooth buds, i.e. methods developed by Gustafson and Koch, Nolli, Haavikko, and Moorees, as well as the Demirjian method used in this study [4]. It was selected by the authors due to its high accuracy, the use of standard X-ray projection for analysis (and thus no difficulties in retrospective analysis and easy access to documentation), and due to the fact that it is widely cited in the bibliography, thus making it possible to compare the results.

Unfortunately, at present, there are few studies comparing dental and calendar age in the Polish population. The results obtained by Zatylna et al. in their studies carried out in 2012 differ from the outcomes of the authors - the dental age was higher than the chronological age, which was more pronounced among girls [5]. Zatylna et al. considered the average dental and calendar age of children, which could have affected the result. The difference between the calendar and dental age was 8.5 months for girls, 3.5 months for boys, and 6 months for all the patients. Similarly, Różyło-Kalinowska et al. established that the Demirjian method inflates the den- tal age by about 0.317 years in girls and 0.3 years in boys. The study was conducted in the Polish population in 994 patients aged between 6 and 16 years. In both groups, a markedly accelerated dental age was observed in sixyear-old children, while the differences in the older study groups were ever smaller [6]. Children under seven years old were not taken into account in the study. Nevertheless, in the youngest group, i.e. 7-9 years, the dental age was about 2.4 months ahead of calendar maturation, while different results were obtained in the remaining groups, in which the calendar age was ahead of the dental age. Additionally, the older the group, the greater the difference. The last group presented with the difference of 10.3 months of delay of dental age.

In the studied conducted by Szafrańska-Perkowska the dental age was in compliance with calendar maturation for $50 \%$ of the studied inhabitants of Białystok. Dental age delay was found in $37 \%$ of girls and $35 \%$ of boys, while acceleration was observed in $10 \%$ of girls and $17 \%$ of boys. The study was conducted among the inhabitants of Białystok. The age of 1044 children between four and eight years old was analysed with a breakdown by gender. The dental age was determined using growth charts made in 1960 by Cieślik et al. [7]. The differences could result from several factors. The dental age was determined using a different method than in the presented article. Moreover, the studies were conducted almost 20 years ago, and the dynamics of changes in the development rate of the Polish population may also impact the acceleration/retardation of teeth eruption. The aforementioned difference may clearly indicate the significance of updating current data and adapting standards to the present situation.

Analysing the available studies, Sobieska et al. obtained similar results to those presented. The studies conducted at the Medical University of Warsaw on a group of 540 girls and 462 boys aged 2.5-17 years, showed a rise in the dental age in patients in groups below eight 
years old using the Demirjian method. In the presented analysis, such a phenomenon was observed in the group aged between seven and nine years old [8].

It should be mentioned that Demirjian et al. described their authorial method of assessing the dental age in 1973 in the French-Canadian, not the Polish, population. According to many foreign studies conducted in various populations, the dental age determined by the Demirjian method is ahead of the calendar age [9-12]. Some of these analyses provide results that are similar to those presented. Liversidge et al. concluded that the dental age assessed using the Demirjian method overestimates the actual age in younger patients. The age range in the study was 3-15 years [13]. Also, German authors Frucht et al. examined a group of 1003 girls and boys aged 2-20 years, and they suggested that the Demirjian method should be adjusted to local standards [14].

Both the cited and presented studies indicate that there is a significant discrepancy between the dental age determined according to tables originally developed by Demirjian and the actual chronological age in the Polish population. Because there is little current research on the development of children, it is important to analyse this problem thoroughly and to create current standards for the Polish population.

The selection of orthodontic treatment depends on several factors, such as malocclusion, its exacerbation, and the patient's developmental age. According to the Rassol's research works [15], there is only a slight correlation between the stage of dental and skeletal development. Nonetheless, dental age should be one of the elements taken into account when planning orthodontic treatment.

In the case of skeletal malocclusion, there are three possibilities of management: growth modification with orthopaedic treatment, orthodontic camouflage, or interdisciplinary orthodontic and surgical treatment. The selection of treatment depends, among other things, on the patient's stage of development. Provided that the patient's skeletal age permits the change of direction and growth rate of the bone bases, the following methods of maxillofacial orthopaedics can be used: Delaire mask, Headgear brace, or functional orthodontic brace - removable or fixed. As demonstrated by the studies conducted by Baccetti [16], the stability of the results obtained during the treatment periodically accelerating the mandible growth largely depends on the obtained lateral tooth occlusion. Therefore, information concerning the time of premolar eruption may be of great importance in obtaining a permanent and stable occlusion after functional treatment and may affect decisions regarding the age of initiation of such therapy $[17,18]$. The estimated age of the eruption of the permanent teeth is also important for early orthodontic treatment of disorders related to crowding of teeth and lack of space for the eruption of permanent teeth. According to Kjellgren and Hotz, the moment of initiation of serial extractions [19] may significantly depend on the estimated age of the eruption of the subsequent permanent teeth.

The assessment of the position and prediction of possible non-eruption of permanent teeth - especially canine teeth - constitutes another problem, which depends to a large extent on the control of the age of tooth eruption. The implementation of the procedure described by Kurol [20] may depend on the appropriate $\mathrm{X}$-ray diagnostics, which should be applied adequately early, as well as on the assessment of the position of the canine teeth in the pantomographic image. It all depends on an initial assessment of the deviation from the planned age of the eruption of the permanent teeth.

According to the presented studies, on the one hand, the development of dentition is ahead of the chronological age in younger children, and on the other hand, the growth and eruption of teeth is retarded at the later age, compared to the studies conducted by Demirjian. When conducting orthodontic treatment, it should be borne in mind that the patient's dental age may not be consistent with widely known data, and the estimation of whether it is retarded or accelerated in comparison with that data also depends on the chronological age.

All the aforementioned considerations indicate the importance of such an assessment for planning prophylaxis and refunded orthodontic treatment in a given population. Currently, the National Health Fund refunds removable orthodontic braces in children up to the age of 12 years old, regardless of their biological development stage, dental age, or gender. However, taking into account the results of the analysis carried out by the authors in the population of Polish children, the chronological age is ahead of the dental maturation, and therefore it would be appropriate to include the assessment of the dental age with regard to reimbursement rules for orthodontic treatment.

Apart from the influence on orthodontic treatment planning, as discussed earlier, the assessment of the dental age may affect the reliability of anthropological and criminal anthropology studies. Obtaining the most upto-date data possible, collected from a specific population, may constitute the sine qua non condition of reliable identification of the age of children in criminological investigations and court proceedings. Data obtained for the purpose of this study, as well as information gathered by other authors, clearly indicate that the standards originally set by Demirjian may be significantly misleading if applied to the contemporary lower Silesian population.

\section{CONCLUSIONS}

In the analysed group the dental age was accelerated in the period of early mixed dentition and delayed in the late mixed or early permanent dentition stage, in relation to the chronological age. 
Therapeutic decisions made by the orthodontist should be based on the analysis of the child's actual dental age and should not take into account the chronological age.

\section{CONFLICT OF INTEREST}

The authors declare no potential conflicts of interest with respect to the research, authorship, and/or publication of this article.

\section{References}

1. Sołtyszewski I, Młodziejowski B, Płoski R, Pepiński W, Janica J. Kryminalistyczne i sądowo-lekarskie metody identyfikacji zwłok i szczątków ludzkich. Problemy Kryminalistyki 2003; 239: 7-10.

2. Demirjian A. A new system of dental age assessment. Hum Biol 1973; 45: 211-227.

3. Roberts GJ, Parekh S, Petrie A, Lucas VS. Dental age assessment (DAA): a simple method for children and emerging adults. $\mathrm{Br}$ Dent J 2008; 204: 192-193.

4. Sobieska E, Fester A, Nieborak M, Zadurska M. Metody oceny wieku zębowego u pacjentów w wieku rozwojowym - przegląd piśmiennictwa. Forum Ortod 2015; 11: 36-48.

5. Zatylna N, Rogowska K, Kozanecka A. Porównanie wieku zębowego dziewcząt i chłopców w wieku 6-12 lat z zastosowaniem metody Demirjiana. Dent Med Probl 2013; 50: 64-70.

6. Różyło-Kalinowska I, Kiworkowa-Rączkowska E, Kalinowski P. Dental age in Central Poland. Forensic Sci Int 2008; 174: 207-216.

7. Cieślik J. Dziecko Poznańskie '90. Wzrastanie, dojrzewanie, normy i metody oceny rozwoju. Poznań: Wydawnictwo Naukowe Bogucki; 1994, s. 30-31, 123-152.

8. Sobieska E, Fester A, Nieborak M, Zadurska M. Assessment of the dental age of children in the Polish population with comparison of the Demirjian and the Willems methods. Med Sci Monit 2018; 24: 8315-8321.

9. Feijoo G, Barberia E, De Nova J, Prieto JL. Permanent teeth development in a Spanish sample. Application to dental age estimation. Forensic Sci Int 2012; 214: 213.e1-6.

10. Nik-Hussein NN, Kee KM, Gan P. Validity of Demirjian and Willems methods for dental age estimation for Malaysian children aged 5-15 yrs old. Forensic Sci Int 2011; 204: 208.e1-6.

11. Tunc ES, Koyuturk AE. Dental age assessment using Demirjian's method on northern Turkish children. Forensic Sci Int 2008; 175: 23-61.

12. Willems G, Olmen AV, Spiessens B, Carels C. Dental age estimation in Belgian children: Demirjian's technique revisited. J Forensic Sci 2001; 46: 893-895.

13. Liversidge HM, Smith BH, Maber M. Bias and accuracy of age estimation using developing teeth in 946 children. Am J Phys Anthropol 2010; 143: 545-554.

14. Frucht S, Schnegelsberg C, Schulte-Mönting J, Rose E, Jonas I. Dental age in southwest Germany. A radiographic study. J Orofac Orthop 2000; 61: 318-329.

15. Rasool G, Bashir U, Kundi IU. Comparative evaluation between cervical vertebrae and hand-wrist maturation for assessment of skeletal maturity orthodontic patients. Pak Oral Dental J 2010; 30: 85-95.

16. Baccetti T, Franchi L, McNamara JA. The Cervical Vertebral Maturation (CVM) method for the assessment of optimal treatment timing in dentofacial orthopedics. Semin Orthod 2005; 11: 119-129.

17. Vetlesen Westwood P, McNamara JA, Baccetti T, Franchi L, Sarver DM. Long-term effects of Class III treatment with rapid maxillary expansion and facemask therapy followed by fixed appliances. Am J Orthod Dentofacial Orthop 2003; 3: 306-320.
18. Franchi L, Baccetti T, McNamara JA. Postpubertal assessment of treatment timing for maxillary expansion and protraction therapy followed by fixed appliances. Am J Orthod Dentofacial Orthop 2004; 5: 555-568.

19. Kjellgren B. Serial extraction as a corrective procedure in dental orthopedic therapy. Acta Odontol Scand 1948; 8: 17-43.

20. Ericson S, Kurol J. Early treatment of palatally erupting maxillary canines by extraction of the primary canines. Eur J Orthodont 1988; 10: 283-295. 